\title{
First report of Fusarium equiseti causing stem rot disease of grape (Vitis vinifera L.) in Afghanistan
}

\author{
Nasir Ahmed Rajput ${ }^{1,2}$ - Bakhat Zaman ${ }^{2,3} \cdot$ Chao Huo $^{1} \cdot$ JiFen Cao $^{1} \cdot$ Muhammad Atiq $^{2}$. Abdul Mubeen Lodhi ${ }^{4}$. \\ Rehana Naz Syed ${ }^{4} \cdot$ Babar Khan $^{2} \cdot$ Owais Iqbal $^{4} \cdot$ Zhijian Zhao $^{1}$
}

Received: 13 October 2019 / Accepted: 6 April 2020 / Published online: 4 May 2020

(C) Società Italiana di Patologia Vegetale (S.I.Pa.V.) 2020

Keywords Grape vines $\cdot$ Stem rot $\cdot$ Fusarium equiseti $\cdot$ Afghanistan

During 2017, grapevines were observed with an unknown disease in Nari, Kunar province of Afghanistan. The disease was characterized by the appearance of small to large circular brown color spots on vine stem. These spots gradually increased in size and turned purplish brown to dark brown. Affected stems were collected from different fields and surface disinfected, PDA plates were incubated at $25^{\circ} \mathrm{C}$ for $3-4$ days. The results revealed the consistent association of Fusarium equiseti. On PDA, the fungus produced colonies with white dense aerial mycelium which later turned deep olive in colour in center. Macroconidia were 5-6 septate, $(1.6-2.4 \times 27-38 \mu \mathrm{m})$, well developed, with prominent dorsiventral, curvature, falcate, thick-walled, moderately curved, short and elongated apical cell, and well-known foot shaped basal cell. Microconidia were not found. Conidiophores were branched or unbranched, bearing monophialides. Chlamydospores were produced abundant-

Zhijian Zhao

zhijianzhao@hotmail.com; zhijianzhao@gmail.com

Industrial Crops Institute, Yunnan Academy of Agricultural Sciences, Kunming, China

2 Department of Plant Pathology, University of Agriculture, Faisalabad, Pakistan

3 Ministry of Rural Rehabilitation and Development, Kabul, Afghanistan

4 Faculty of Plant Protection, Sindh Agriculture University, Tandojam, Pakistan ly on the aerial mycelium, formed in clumps, with flat or roughened walls. In pathogenicity test, 20 young shoots of threeyear-old grape plant were inoculated with $1 \mathrm{~cm}$ mycelial plug and maintained in a greenhouse at $28^{\circ} \mathrm{C}$ with $70 \%$ RH. Typical rot symptoms on the grape stems were clearly detected after 14 dpi on all the inoculated plants. No symptoms were found on 20 control stems inoculated with only PDA plugs. Re-isolation of $F$. equiseti from the inoculated plants fulfilled the Koch's postulates. Internal transcribed spacer and nuclear large subunit ribosomal DNA of both pathogenic isolates NAR08 and NAR16 were amplified and sequenced with the primers ITS1/ITS-4 and D1D2-NL1/D1D2-NL4, respectively (Hesham et al. 2014). Sequences were deposited in GenBank (ITS, MF039884, MF039885 and LSU, MF039882, MF039883) and shared $99 \%$ similarity with the published ITS (KX588103, KY426430) and LSU (KY411824, KJ126466) sequences of $F$. equiseti. To our knowledge, this is the first report of $F$. equiseti causing stem rot on grapes in Afghanistan.

\section{Reference}

Hesham AEL, Wambui V, Jo HO, Maina JM (2014) Phylogenetic analysis of isolated biofuel yeasts based on 5.8 S-ITS rDNA and D1/D2 26S rDNA sequences. J Genet Eng Biotechnol 12:37-43

Publisher's note Springer Nature remains neutral with regard to jurisdictional claims in published maps and institutional affiliations. 